\title{
"Hipocrisia": a visão dos gays cabo-verdianos sobre o seu próprio sistema de gênero
}

\author{
Francisco Miguel \\ Doutorando do PPGAS/ UnB
}

\begin{abstract}
Resumo: Neste artigo, pretendo apresentar um quadro das noções de gênero e identidade sexual em Cabo Verde, suas estabilidades e tensões, a partir da perspectiva privilegiada dos sujeitos homossexuais daquele país. Nesse sentido, a categoria êmica "hipocrisia" apareceu recorrentemente nos discursos dos sujeitos homossexuais pesquisados. Esta categoria de acusação parece denunciar ao mesmo tempo um silenciamento da sociedade mais ampla e uma contradição entre moralidades e práticas operantes em Cabo Verde no tema da homossexualidade. Meu argumento é que mais do que uma simples crítica moral dos sujeitos homossexuais aos seus compatriotas e a sua sociedade em geral, a categoria pode nomear uma perspectiva do sistema de gênero caboverdiano de relativa estabilidade, que chamei de "Sistema Hipocrisia".
\end{abstract}

África;

Palavras-chave: Hipocrisia; Gênero; Homossexualidade; Cabo Verde; 


\title{
"Hipocrisia": Cabo Verdeans gays' perspective on their own gender system
}

\begin{abstract}
In this article, I present a framework of gender and sexual identity notions in Cabo Verde, their stabilities and tensions, from the perspective of the native homosexual people. In this sense, the emic category "hipocrisia" (hypocrisy) appeared repeatedly in the speeches of those people. This accusatory category seems to report both a silence and a contradiction between morals and operative practices in Cape Verde on the theme of homosexuality. My argument is that more than a simple moral criticism of homosexual people to their compatriots and their society in general, the category may appoint a perspective of Cape Verdean gender system of relative stability, which I have called "Hypocrisy System".
\end{abstract}

Keywords: Hipocrisy; Gender; Homosexuality; Cabo Verde; Africa.

\section{"Hipocrisia": la visión de los gays de Cabo Verde sobre su propio sistema de género}

Resúmen: En este artículo, tengo la intención de presentar un cuadro de las nociones de género y de identidad sexual en Cabo Verde, su estabilidad y la tensión, desde el punto privilegiado de los sujetos homosexuales de ese país. En este sentido, la categoría emic "hipocresía" apareció en varias ocasiones en los discursos de los sujetos homosexuales encuestados. En esta categoría se queja parece reportar tanto un silenciamiento de la sociedad en general y una contradicción entre la moral y las prácticas operativas en Cabo Verde en el tema de la homosexualidad. Mi argumento es que más de una crítica moral sencilla de los homosexuales sometidos a sus compatriotas y su sociedad en general, la categoría podrá nombrar una perspectiva de caboverdiano sistema de género de la estabilidad relativa, lo que he llamado "Sistema de hipocresía". África.

Palabras clave: Hipocresía; Género; Homosexualidad; Cabo Verde; 


\section{Introdução}

Colônia de Portugal até 1975, Cabo Verde é um país arquipelágico africano composto por dez ilhas, sendo nove delas habitadas. O arquipélago fica localizado na Macaronésia, Atlântico Norte, na latitude de Dakar. Faz parte da área etnográfica também conhecida como Costa da Guiné. O país tem aproximadamente 500 mil habitantes e tem como sistema de governo uma república democrática semi-presidencial, de relativa estabilidade política desde a independência. Ainda, tem se mostrado um estado garantidor das liberdades individuais, à diferença de outros países do continente (Miguel, 2014). A língua oficial é o português, todavia o país tem o crioulo cabo-verdiano - de base lexical portuguesa, mas estrutura gramatical africana - como língua corrente nas ruas.

Apresentado brevemente o país, neste artigo pretendo elaborar um quadro das noções de gênero e identidade sexual em Cabo Verde, suas estabilidades e tensões, a partir da perspectiva privilegiada dos sujeitos homossexuais daquele país. Assim sendo, não me deterei extensivamente nos discursos acadêmicos sobre as relações de gênero mais amplas no país, suas classificações etc., conquanto meu objetivo principal neste trabalho será o de, a partir de pesquisa etnográfica1, compreender a percepção particular dos sujeitos homossexuais e travestes2 do arquipélago. A forma como eles percebem o sistema de gênero no qual estão inseridos nos encaminhará para compreender as bases semânticas nas quais eles mesmos articulam suas identidades e agências no mundo.

Nesse sentido, a categoria êmica "hipocrisia" apareceu recorrentemente nos discursos dos sujeitos homossexuais pesquisados. Esta categoria de acusação parece denunciar ao mesmo tempo um silenciamento da sociedade cabo-verdiana em relação à homossexualidade e uma contradição entre moralidades e práticas operantes em Cabo Verde quando este é o assunto. Ao analisar sua própria sociedade, diversos interlocutores gays apontaram-na como "hipócrita", dirigindo extensivamente o mesmo termo a alguns dos indivíduos que dela façam parte. Meu argumento é que mais do que uma simples crítica moral dos sujeitos homossexuais aos seus compatriotas e a sua sociedade em geral, a categoria pode nomear uma perspectiva do sistema de gênero caboverdiano de relativa estabilidade, que chamarei de "Sistema Hipocrisia".

1 Este artigo é fruto de minha pesquisa de mestrado, em que realizei um trabalho de campo de 43 dias, em 2013, nas Ilhas de Santiago e São Vicente, cujas principais cidades são, respectivamente, Praia e Mindelo. Dei especial atenção para esta última. Entre meus principais interlocutores havia artistas, que trabalhavam como atores, carnavalescos e costureiros. Havia também estudantes das universidades locais em cursos de jornalismo, direito, turismo e ciências sociais, havia produtores de eventos, um professor de educação física, outro de inglês, um cabeleireiro e maquiador e um escriturário em uma companhia marítima. Entre as travestes, há quem tivesse seu pequeno comércio, outras se prostituíam e algumas delas ainda estudavam. O intuito da pesquisa era etnografar a homossociabilidade, a homossexualidade e o movimento LGBT local.

2 É difícil estabilizar na escrita identidades sexuais que são etnograficamente fluidas. Assim, em Cabo Verde, a fronteira que separa gays e travestes é muito tênue e porosa. A identidade traveste diz respeito não somente a classificações por intensidades de masculinização/feminilização dos corpos, mas também reverbera posições de classe. No geral, porém, as travestes são aquelas que nasceram com órgãos genitais masculinos, são pessoas mais pobres que, ao desejarem ser mulher mantêm seus corpos ao máximo feminilizados e que advogam, por vezes, esta identidade para si. A grafia distinta pretende marcar não somente uma distinção fonética da língua crioula em relação à língua portuguesa, mas também demarcar que a identidade traveste se diferencia culturalmente das travestis brasileiras, por nunca terem seus corpos transformados por próteses de silicone e por tratamentos hormonais, tecnologias nem sempre desejáveis, não disponíveis localmente e inviáveis do ponto de vista econômico para elas. 


\section{"Sistema Hipocrisia"}

Do ponto de vista dos homossexuais cabo-verdianos, "hipocrisia" é a categoria moral que descreve (e acusa) dois aspectos distintos, mas interconectados, do sistema de gênero em Cabo Verde. Assim, o termo serve tanto para acusar o típico silenciamento da sociedade cabo-verdiana em relação ao dado empírico da (homo)sexualidade3, quanto para denunciar a suposta contradição entre os valores heteronormativos dessa sociedade e as práticas (homo)sexuais que nela convivem. Antes de tratar da "hipocrisia", contudo, é preciso passar brevemente em vista pelo sistema de gênero em Cabo Verde.

Aproximando-se de muitas pesquisas sobre gênero e masculinidades em África (Ampofo \& Boateng, 2013), as etnografias sobre o sistema de gênero cabo-verdiano nos oferecem um quadro que opera estruturalmente de forma binária e sexista (Rodrigues, 2010:105), enquadrando ao máximo dentro dele os diversos exercícios de sexualidade que fogem ao conjunto de práticas e identidades consideradas "heterossexuais". Vários autores têm apontado uma tendência "patriarcal" como característica importante da sociedade caboverdiana (Lobo, 2012:67; Rodrigues, 2010:105; Miranda, 2013:66), ainda que outros a tomem para empreender sua desconstrução teórica e prática, a partir da exposição do papel de destaque das mulheres (Rodrigues, 2007). A "dominação masculina" é evidente para alguns autores (Rodrigues, 2010:105), enquanto outros têm tratado da reprodução de uma "masculinidade hegemônica" que é incorporada inclusive pelas mulheres cabo-verdianas (Massart, 2005). Outros já trataram da questão mostrando a ambiguidade crioula entre o ideal de patriarcado e uma matrifocalidade na prática (Dias, 2000:184).

Tendo em vista o "patriarcado" como suposto sistema de organização social em Cabo Verde, nele encontram-se referências sobre uma predisposição êmica que naturaliza a poligamia masculina (Rodrigues, 2007:141; Vasconcelos, 2012:60; Massart, 2005; Miranda, 2013:17), uma divisão do trabalho com ênfase no gênero (Lobo, 2007:71; Massart, 2005), em que se destaca a distância relativa dos homens do universo doméstico (Lobo, 2012:67-8,75; Rodrigues, 2007:140-1; Massart, 2005), e uma masculinidade heterocentrada (Rodrigues, 2010:105), que se define pela hétero e hipersexualidade (Rodrigues, 2007:139141). Além disso, a masculinidade é construída em Cabo Verde, sobretudo, através da exibição pública de virilidade (Miranda, 2013:77). Ela é performatizada através de ações teatralizadas, simulações, muita exibição pública, discussões e a depreciação do feminino (Miranda, 2013:81). Todavia, para alguns, devido a novas dinâmicas culturais e econômicas em Cabo Verde, esta masculinidade estaria, atualmente, passando por uma crise (Bordonaro, 2012:132; Miranda, 2013:106). Outros negam tal crise, demonstrando as continuidades da "masculinidade hegemônica" local, inclusive na melhor aceitação da homossexualidade pelos homens em geral (Massart, 2013:311).

Deste conjunto de informações, as quais eu não tenho pretensão de discutir profundamente, pois fugiria do escopo deste trabalho, é importante destacar pelo menos duas: 1) que as relações de gênero em Cabo Verde tendem a

3 Sempre que me referir à "(homo)sexualidade", estarei com isso querendo me referir tanto à sexualidade mais ampla dos cabo-verdianos, quanto às práticas sexuais entre indivíduos do mesmo sexo, que estão englobadas. 
ser assimétricas e a dominação masculina neste país é um dado que tem sido apontado tanto pelas ciências sociais nativas quanto estrangeiras; 2) na cultura cabo-verdiana a masculinidade é construída numa relação de distância com o ambiente doméstico e com uma conjugalidade tipicamente burguesa. Como veremos, as relações entre indivíduos do mesmo sexo no arquipélago reproduziriam e atualizariam essas assimetrias e essa dissociação ora mencionadas (Lobo \& Miguel, 2015).

Ainda que em dúvida quanto a sua universalidade, tomo o pressuposto da teoria queer de que para a existência de um sistema de matriz heterossexual, a "homossexualidade" é o contraposto lógico necessário. Neste sentido, é de se esperar que à "homossexualidade" tenha se conferido algum lugar dentro do sistema de gênero cabo-verdiano. Este lugar, porém, pode variar nas ditas "sociedades patriarcais" e certamente em Cabo Verde, a "homossexualidade" não é assimilada culturalmente da mesma forma que em outras sociedades deste mesmo tipo, tampouco é formulada internamente de maneira homogênea. Há modelos em competição (Fry, 1982:91).

É sob a inspiração destes modelos tipológicos recriados por Fry (1982), que pretendo diferenciar não somente dois sentidos da categoria "hipocrisia" na perspectiva dos homossexuais a respeito do sistema de gênero cabo-verdiano (o silenciamento e a contradição), como diferenciar as próprias experiências em relação à sexualidade (modelo hierárquico e modelo simétrico)4.

\section{Modelos hierárquico e simétrico}

Assim, de um lado, tem-se um modelo hierárquico hegemônico de sexualidade masculina no arquipélago, em que emergem as figuras dos "homens" e das "bichas", cujos comportamentos sexuais respectivamente serão no plano ideal "ativo" e "passivo", reproduzindo a dominação masculina sobre o feminino; por outro lado, percebo a emergência de um modelo sexual tipicamente igualitário ou simétrico, onde surge a figura do "homossexual" masculino, cujo comportamento sexual (se "ativo" ou "passivo") não é o diacrítico por excelência entre esses sujeitos "homossexuais".

Operarei analiticamente com esses modelos tipológicos, pois eles contribuem para o trabalho de estabilização, pressuposto em uma peça antropológica. E, apesar desse modelo teórico ter sido gerado em outro quadro de referência empírica, o Brasil, serve como grande inspiração ao caso caboverdiano. Por outro lado, a teoria queer já nos relembrou que estes modelos nunca são realizados na sua plenitude pelos sujeitos. É, portanto, nas repetições dos atos performativos destes, em suas bricolagens de signos de sexualidade dispostos na cultura, é que se cria a falsa aparência de substância de gênero (e desses modelos). Portanto, nem todos os "homoafectivos" viverão de fato relações simétricas com outros "homoafectivos", tampouco, no outro modelo, todos os "homens" serão sempre "ativos" ou todas as "bichas" sempre "passivas" 5. Como sugere a teoria queer, resta-nos estudar as performatividades

4 Modelos que seriam inspirados nas ideias de Louis Dumont (1997), como o próprio Fry fez questão de enfatizar certa vez (Comunicação pessoal).

5 Desde o início do trabalho, Fry alerta deliberadamente para o fato de se propor analisar representações sociais, discursos e retóricas e não as práticas sexuais em si, o que lhe proporciona criar modelos ideais. Mas em uma nota de fim, o autor é claro quanto a essa fluidez ao dizer que os "entendidos" - uma figura análoga ao aqui "gay", supostamente simétricos aos parceiros - preferem manter relações sexuais com os classificados "homens" e não com outros “entendidos", apesar da "regra” do modelo igualitário (Fry, 1982:113). 
de gênero empreendidas pelos sujeitos, para perceber os deslocamentos neste empreendimento.

Por último, pretendo transformar a categoria "hipocrisia", verificadas nas duas das maiores ilhas deste país arquipelágico, São Vicente e Santiago, de uma acusação moral nativa em uma categoria analítica, que dê conta da perspectiva da população "gay"6 cabo-verdiana a respeito do sistema de gênero no qual estão inseridos. Assim, o "Sistema Hipocrisia" - com letras maiúsculas - será sempre aqui a objetivação que fiz, a partir de suas próprias enunciações, para estabilizar a percepção dos gays cabo-verdianos em relação ao seu próprio sistema de gênero. A categoria "hipocrisia" é êmica, mas passou por um processo de esvaziamento da carga moral para se tornar uma categoria de análise objetificante e, portanto, virtual. Há no que chamo de Sistema Hipocrisia os dois modelos propostos por Fry (1982) e, diz a população gay cabo-verdiana, um silenciamento sobre suas existências e uma contradição entre valores e práticas sexuais. Vejamos o que seja isso tudo.

\section{Da pa dodu}

Nesta subseção, pretendo me deter no primeiro sentido êmico de "hipocrisia", ou seja, quando ela assume a forma de crítica dos sujeitos gays sobre o silenciamento (ou não confrontação) da sociedade cabo-verdiana em relação à existência empírica da homossexualidade. Farei isso a partir dos meus dados e do diálogo com a pesquisa de mestrado da socióloga cabo-verdiana Claudia Rodrigues7, que colheu depoimentos dos "homoafectivos"8, que vivem relações conjugalizadas e de coabitação na capital do país.

Antes de dar prosseguimento, é preciso deixar claro que dialogo com os dados da socióloga Claudia Rodrigues, porque eles nos dizem muito acerca de um dos sentidos que a categoria "hipocrisia" ganha entre os homossexuais de Cabo Verde - o silenciamento. Contudo, eu mesmo pude tanto em meu campo mais longo no Mindelo, quanto nas minhas rápidas incursões na capital Praia, perceber que o silenciamento em relação à homossexualidade extravasa não só o limite físico da Ilha de Santiago, como os limites simbólicos da classe dominante, na qual Rodrigues fez pesquisa. Tal fato me permitiria generalizar o chamado Sistema Hipocrisia, incorporando as percepções dos homossexuais

6 Usarei a categoria "gay" sempre que precisar me referir a todos os sujeitos que se reconheçam a partir de uma identidade sexual não heterossexual, sejam eles "homossexuais", "homoafectivos", "travestes", "tchinda", "paneleiros" ou "bichas". Para um melhor entendimento das identidades sexuais em Cabo Verde, ver Miguel, 2014.

7 Uma ressalva importante a ser feita é que Rodrigues pesquisou membros da elite da capital do país, a cidade da Praia (Rodrigues, 2010:14), com exceção de uma traveste da periferia. A questão da classe sócio-econômica é um vetor fundamental para a conformação de diversos discursos, inclusive discursos que forjam diacríticos mesmo dentro de um suposto grupo, como os chamados LGBT. O que quero dizer é que se deve levar em conta que os relatos por ela obtidos possuem um viés de classe inegável - como a conjugalidade romantizada em contraposição à "promiscuidade", o interesse nos direitos civis e patrimoniais, o poder econômico e simbólico para viver uma vida "dentro do armário", a crítica do travestismo e da passividade das "bichas" etc. Como veremos, Rodrigues pesquisou indivíduos que se aproximariam de um sistema moderno de experiência da "homossexualidade", que Peter Fry já chamou de "o sistema B", onde o ato sexual dramatizaria a igualdade e a simetria (Fry, 1982:94). Contudo, analisar os "homoafectivos" possibilitará vislumbrar um sentido de "hipocrisia", qual seja, o de silenciamento, difuso na população gay do país. Para verificar os diacríticos discursivos dos homossexuais da elite cabo-verdiana para com os das classes populares, ver Rodrigues, 2010:81.

8 Rodrigues esclarece que optou pelo termo "homoafectivo", ao invés de outros termos para designar seus interlocutores, por considerar que este termo "êmico", apesar de importado do Brasil, daria conta de uma totalidade mais ampla que apenas a dimensão sexual (Rodrigues, 2010:3). Ainda que concorde com a aplicação do conceito no trabalho da socióloga, em meu trabalho, porém, usarei o termo "homoafectivo" apenas para me dirigir aos seus interlocutores. Neste trabalho os termos "homossexual" e "gay" se mostram mais convenientes tendo em vista que: 1) ainda que precário do ponto de vista de sua capacidade de conferir identidade, estes são termos êmicos operantes e que atribuem significados em Cabo Verde; 2) esta etnografia, pelos rumos que ela mesmo tomou, pretendeu ter como foco a (homo)sexualidade dos cabo-verdianos; 3) O afeto entre sujeitos homossexuais na Ilha de São Vicente é muitas vezes negado como possível (Miguel, 2014) 
tanto de Praia quanto do Mindelo. Mas ainda assim, aviso ao leitor que o "Sistema Hipocrisia" enquanto categoria analítica não passa de um exercício hipotético, posto à prova.

Dito isso, embarquemos no depoimento de Joana, uma das mulheres "homoafectivas", interlocutora de Rodrigues na capital:

\begin{abstract}
Joana: Resumindo... o que é que eu acho é que realmente seja muito hipócrita... enquanto que as pessoas não são confrontadas até gostam de falar... cada uma dá a impressão de que gosta de mostrar que sabe mais ou que conhece mais pormenores ah nunca fui confrontada também tudo que apareceu de maldoso é sempre anónimo... portanto concordo em tudo... é uma sociedade hipócrita em relação a esse tipo de relacionamento (Rodrigues, 2010:89).
\end{abstract}

O que se percebe neste relato é que a "hipocrisia" é aqui uma acusação moral dos indivíduos "homoafectivos" em relação àqueles outros indivíduos de sua sociedade que, supostamente incapazes de confrontar a realidade da existência da homossexualidade diante dos próprios homossexuais, tratam-na como uma interdição, algo a não ser dito ou, se dito, longe da "frontalidade" dos homossexuais: "Tudo que apareceu de maldoso é sempre anônimo” (Rodrigues, 2010:89).

A forma em que a categoria "hipocrisia" frequentemente ganha seu sentido nesta elite, ou seja, como sendo uma acusação dirigida a pessoas e não claramente como uma crítica social mais radical está também diretamente ligada às características da classe social na qual é elaborada. Rodrigues nos mostra o ethos individualista desta elite "homoafectiva", que busca se "acobertar":

Na cidade da Praia, apesar de toda essa busca para a modernidade/modernização, não existe, de forma evidente, uma cultura gay, e as manifestações homoafectivas têm surgido de forma bastante individualizada e discreta (ou mesmo escondida). [...] Os homoafectivos da elite da sociedade praiense, pelo contrário, estão bastante retraídos e individualizados: não há uma busca por uma assumpção pública, e, por vezes existe um esforço de "encobertamento" (Rodrigues, 2010:56).

Contudo, mesmo entre sujeitos dessa elite, é possível captar uma crítica sistêmica, como no depoimento de Maria, companheira de Joana e também interlocutora de Rodrigues. Maria dirá que sua

sociedade desde que não seja confrontada com uma certa actividade de forma bastante explícita, ela é hipócrita o suficiente para não ser frontal, nem em termos de perguntar para tirar dúvidas nem em termos de agredir (Rodrigues, 2010:89).

Tal crítica social, contudo, não levará essa elite "homoafectiva" de Praia ao enfrentamento do status quo. A hipótese de Rodrigues é de que aos "homoafectivos" da elite da Praia, detentores de capital econômico, intelectual e artístico, portanto detentores de poder na sociedade praiense (Rodrigues, 2010:55), não lhes têm interessado confrontar politicamente a estrutura de poder existente, inclusive a heteronormatividade, pois são, em outros aspectos, os próprios beneficiários dessa estrutura. Em outras palavras, não parece vantajoso aos "homoafectivos" da Praia colocar em risco seus privilégios de elite em prol de uma identidade sexual (Rodrigues, 2010:100).

A partir dessa perspectiva classista e conservadora da elite gay praiense, a "hipocrisia" parece ganhar o sentido de uma crítica moral àqueles que ousam desestabilizar a hierarquia de classe posta, ao colocar em questão a sexualidade desviante dos estabelecidos membros dessa elite. A queixa então desses membros "homoafectivos" da elite se torna moralizante e não aspira a um movimento de transformação social mais profunda. Constatação que levará 
Rodrigues a uma auto-reflexão crítica sobre não ser da obrigação dos sujeitos "homoafectivos", que estes participem em movimentos sociais por seus supostos direitos (Rodrigues, 2010:91).

Parece desnecessário dizer que em um sistema político democrático, como o é o cabo-verdiano, não é obrigatória, a qualquer indivíduo, a militância por seus supostos direitos. Mais importante do que constatar isso é perceber, por um lado, a dinâmica nativa de desvencilhamento de rótulos sexuais-identitários, como faz Rodrigues - é verdade - mas, por outro, também perceber os jogos de poder contidos nesta ideologia individualista, que prega a liberdade do indivíduo "autônomo". Nesta ideologia, o indivíduo se supõe desprendido de seus pressupostos de classe. Sugiro que esta ideologia poderia ser uma das possibilidades de explicação para o não engajamento no movimento LGBT desses sujeitos da elite de Praia.

Contudo, parece-me que se trata menos de uma perspectiva deste ou daquele indivíduo. Essa postura cultural de não confrontação das pessoas em relação à homossexualidade, a princípio, teria duas explicações possíveis: por um lado, poderia ser explicado como uma perspectiva pós-moderna de desestabilização das identidades sexuais antes fixas. Ou seja, tratar ou acusar alguém por sua identidade ou orientação sexual parece não mais ser gramatical nos dias de hoje em Cabo Verde. Por outro lado, no caso específico de uma elite, como a pesquisada por Rodrigues, o aspecto cultural da não confrontação ou silenciamento ganha ainda mais força neste grupo, que gozaria positivamente do silêncio social em relação ao seu "desvio".

Mas minha hipótese central é que acima de tudo, há um contexto de relativa "tolerância" com a homossexualidade em Cabo Verde, razão pela qual a "não confrontação" e o "silenciamento", expressos no termo "hipocrisia", são características culturais e não desvios morais, como pensam muitos dos sujeitos gays do país9. E que estas características só permanecem porque gozam de uma ressonância tanto entre os sujeitos "héteros" quanto entre os próprios sujeitos "gays" cabo-verdianos, que também participam destes jogos simbólicos e performativos e, assim, contribuem para a sua manutenção. No capítulo sobre o mandar bocas, em minha dissertação, defendi com mais detalhes a hipótese da tolerância cabo-verdiana (Miguel, 2014). Por ora, creio ser importante estar bem atento aos indícios que os sujeitos homossexuais fornecem a respeito disso, como Maria:

\footnotetext{
Maria: também é assim que não se estaria preparada para um excesso de responsabilidade de ter que empunhar bandeiras... eu não sou muito de assumir causas no sentido de enfrentar... batalhas... Cabral morreu... ãh mas vocês deveria lutar por um lugar ao sol... calma eu tou bem e eu acho que consigo... conseguimos gerir a nossa relação de uma maneira total... as pessoas perguntam vocês já assumiram... nós assumimos para nós nunca fizemos isso de Hellooo... isso nunca existiu... vivemos o nosso dia-a-dia. (Rodrigues, 2010:91, grifo meu)
}

Assim, fica claro desde já que, apesar das reclamações pontuais, de maneira geral, os "homoafectivos" entrevistados por Rodrigues, tanto homens quanto mulheres, vivem "bem", "de uma maneira total”. E eu poderia dizer algo parecido para os meus próprios interlocutores na cidade do Mindelo, na Ilha de São Vicente. Suspeito que os interlocutores "homoafectivos" de Rodrigues não aderem a um movimento LGBT: primeiro, porque, assim como muitos de meus interlocutores no Mindelo, eles já não se afetam ou se sentem representados

9 A literatura sobre homossexualidade em África, inclusive, aponta recorrentemente para uma cultura pan-africana do silêncio em torno dessa questão, que não estaria necessariamente ligado a uma opressão (Epprecht, 1998; Tushabe, 2013; O’Mara, 2013). 
pelas identidades sexuais postas nesta sigla (elas já não seriam mais tão gramaticais atualmente); segundo, existe uma "tolerância" em Cabo Verde em relação à homossexualidade, constatada em muitos momentos pelos próprios sujeitos homossexuais e, que, como já aludi (Miguel, 2014), dificultará portanto bastante a solidificação de um movimento LGBT no arquipélago, porque o "inimigo" a ser combatido - supostamente a "homofobia" - é mais difícil de ser localizado.

A partir dos dados, parece-me evidente que, acima de tudo, não há uma saturação por parte tanto dos interlocutores da Praia como pelos do Mindelo com o silenciamento em relação à (homo)sexualidade - característica cultural marcante da sociedade cabo-verdiana - que os leve a contestar radicalmente o sistema de gênero em seu país. Talvez essas sejam boas chaves para pensar a angústia da socióloga em relação à falta de associativismo dos "homoafectivos" em Praia em torno da questão. Além do mais, esta tese do não associativismo é estranha quando a experiência etnográfica demonstra uma forte tendência associativa no arquipélago, muito conectada aos processos de modernização/cosmopolitização (Miguel, 2014). E, por fim, o movimento associativo LGBT em Cabo Verde, iria surgir justamente pelas mãos das travestes de São Vicente, não por acaso, um dos grupos mais marginalizados da estrutura social daquele país.

De certa forma, Rodrigues corrobora com a constatação do silenciamento da homossexualidade em Cabo Verde quando demonstra a partir do discurso de Joana que a prática difusa da "hipocrisia" (lida aqui, como não confrontação) em relação aos "homoafectivos" não chega a afetar os sujeitos, tamanho é seu assentamento numa tradição corroborada socialmente. Seria somente nas relações diádicas, vindo de "pessoas próximas", que sua interlocutora apontaria como algo que a "magoa mais" (Rodrigues, 2010:93).

Fica claro no depoimento de sua interlocutora Joana que a afetação se dá a partir do momento em que o sujeito tem suas expectativas de reconhecimento frustradas. Tais expectativas, porém, são projetadas sobre os outros mais próximos, a quem se espera certos tipos de lealdade. O depoimento de Joana demonstra que em relação à sociedade mais ampla já não se espera lealdades neste sentido, mas o silêncio em relação à (homo)sexualidade, tão característico dos costumes locais. Assim, a "hipocrisia" (ou a não confrontação), enquanto prática, só se torna um problema para aquele grupo, de fato, quando ela encarna nas pessoas do círculo social daquele sujeito "homoafectivo", que quebram o pacto do não dizer e "tecem ilações", ainda que indiretas.

Sobre a constituição deste silenciamento em Cabo Verde, e mais especificamente na sociedade da Praia, Rodrigues nos oferece uma boa sociologia nativa. Desta vez de Ana, outra interlocutora "homoafectiva" de sua pesquisa:

\footnotetext{
Ana: Ãh... Eu acho que vou usar o termo que usa o crioulo, vamos tentar explicar um bocadinho, ela (a sociedade praiense) age num estilo "do pa dobu" (fingir-se de doido), ou seja, eu entendo que a sociedade não é que seja declaradamente, na minha experiência, homofóbica, mas também não é aberta... há um sistema de alguma hipocrisia, de alguma suposta indiferença de dizer que somos todos iguais desde que não haja nenhuma atitude chocante... mas que esteja aberta eu não diria, eu acho que é mais uma sociedade estilo avestruz, ou "da pa dobu", avestruz que prefere enfiar a cabeça dentro da areia para não enfrentar e não discutir. Eu vi o caso, por exemplo, do jornal Asemana, que provocou uma única reacção, foi a sua, mas não houve mais reacções, mas imagino que haja pessoas que fizeram comentários a favor ou em desfavor, mas não houve muito mais para além disso, é um exemplo para ilustrar o nível de alguma indiferença que possa existir (Rodrigues, 2010:98, grifo meu).
} 
Rodrigues deixa escapar a valiosa dica de sua interlocutora: trata-se de um "sistema". Um sistema nativo que evita confrontos diretos como forma de lidar com o dado empírico da existência pública da homossexualidade, desde que as práticas sexuais e as identidades sejam, ao máximo, veladas. Aliás, deve ser dito que a atitude social em Cabo Verde em relação à homossexualidade parece se assemelhar com atitude social em relação à sexualidade de uma forma mais ampla: as práticas sexuais devem ser mantidas na esfera da privacidade, da intimidade e domesticidade (Lobo \& Miguel, 2015).

A forma como as interlocutoras de Rodrigues descrevem a atitude social diante delas parece se assemelhar a atitude de "indiferença" do próprio Estado cabo-verdiano diante do até então crime de sodomia (Miguel, 2014). Sugiro que assim como os "hipócritas" da atualidade, narrados pelos interlocutores de Rodrigues e pelos meus, o Estado cabo-verdiano também parece ter evitado os confrontos diretos, não levando, aparentemente, ninguém a julgamento até 2004, enquanto vigorou a lei que criminalizava os "vícios contra a natureza" entre eles, a homossexualidade. Mas ao mesmo tempo é dito não ter reconhecido institucionalmente estas pessoas enquanto portadoras de alguns direitos10.

Acerca desse silenciamento do Estado cabo-verdiano, Maritza, uma professora universitária cubana radicada na cidade da Praia, contribuiu insistindo que o tema da homossexualidade era pouco discutido em Cabo Verde e que ainda não entrou na agenda pública. Alegou só lembrar-se de "um expresidente do parlamento ter citado algo sobre os direitos dos homossexuais se enquadrar dentro dos direitos humanos”. Talina, então presidente do ICIEG Instituto Cabo-verdiano para Igualdade e Equidade de Género, que fica na capital do país - é igualmente enfática: "Não há políticas públicas para LGBT ainda. O tema ainda não está na agenda”.

Enfim, tanto na perspectiva de profissionais ligados a um tipo de movimento social que toma a desigualdade de gênero como algo que deve ser combatido e discutido na sociedade, quanto aos próprios "homoafectivos", a sociedade praiense e o Estado cabo-verdiano, assim como parte da sociedade mindelense, "da pa dodu" (dá para doido, tradução livre), ou seja, fingem-se de "doidos" ou que não estão vendo que filhos, vizinhos, colegas de trabalho e parentes são homossexuais. Preferindo não destratar, não tratam, silenciam-se. É claro que esta é apenas uma das hipóteses possíveis para explicar o fato do Estado cabo-verdiano nunca nem ter aplicado as penas sobres "os vícios contra a natureza”, nem ter conferido direitos civis a esta população. Mas uma vez entendido o hábito difuso de silenciamento dos crioulos em relação à (homo)sexualidade, a postura do Estado cabo-verdiano como um espelho dessa sociedade parece uma boa hipótese a se perseguir.

$E$ se engana quem pensar que este é um fluxo unidirecional e simplesmente opressor da sociedade mais ampla ou do Estado em relação a esses grupos minoritários, os LGBT. Este é um processo histórico de retroalimentação entre indivíduos e sociedade que permanece como marca cultural ainda muito evidente na Praia, mais do que no Mindelo. Vejamos a afirmação de Rodrigues diante dos relatos sobre as atitudes que suas interlocutoras tomam diante de sua sociedade: 


\begin{abstract}
Em termos de vivência, e de como esta forma de agir da sociedade as afecta, as duas afirmam que esta situação não as afecta, pois levam a sua vida como querem. E percebe-se que incorporam o agir social da suposta indiferença e não agem como atitudes que possam provocar algum choque. O refreamento das suas manifestações públicas é visto como um sinal de respeito pelos outros (Rodrigues, 2010:99)
\end{abstract}

Podemos ver neste depoimento, naquele de Maria sobre a sua não militância, alegando viver "bem" e de maneira "total" e na negação recorrente da existência de "homofobia" no Mindelo (Miguel, 2014), que se as dinâmicas (homo)sexuais geram alguma dor ou "mágoa", seja na Praia seja no Mindelo, não parece de forma alguma gerar uma situação sociológica insustentável de opressão desses sujeitos, com vistas a uma ruptura radical. A própria Rodrigues traz exemplos de boa relação familiar entre travestes e "homoafectivos" e suas famílias na cidade da Praia (Rodrigues, 2010:67-68,78).

Rodrigues tampouco achou que houvesse perspectivas para a emergência no curto prazo de um movimento LGBT em Cabo Verde (Rodrigues, 2010:107), apesar de ele ter surgido no Mindelo poucos anos depois. O que quero dizer é que parece haver algum equilíbrio ainda que instável nesse sistema em que o silêncio impera e no qual, de certa forma, também se beneficiam os próprios sujeitos gays.

Ainda que meu foco de análise não tenha pretendido ser a população "homoafectiva" da cidade da Praia, na Ilha de Santiago, mas os gays de São Vicente, registro, porém, que os relatos ora expostos nos revelam um aspecto importante do que chamei de Sistema Hipocrisia: a homossexualidade neste país parece ter sido socialmente tolerada desde que fosse silenciada. As relações homoeróticas precisam ocorrer "sem estrilo" (sem escândalo), repetiam-me diversas vezes em crioulo. Assim, a homossexualidade é permeada por interdições inclusive discursivas, entre elas, aquela da acusação direta a um homossexual por sua orientação ou práticas sexuais, seja na ilha de Santiago seja em São Vicente11.

O que parece é que faz parte do funcionamento da matriz heterossexual cabo-verdiana, para usarmos um termo de Butler (1993), conter as sexualidades não heteronormativas. Por um lado, não se confronta os sujeitos homossexuais e, por outro, manda-se bocas.

Mandar bocas é uma expressão idiomática do crioulo cabo-verdiano que permite um conjunto mais ou menos alargado de significados. Pode, portanto, se referir tanto a fazer brincadeiras entre amigos, tidas como inocentes, até operar como deboches, insultos e humilhações. As bocas podem ser dirigidas aos alvos típicos de troças (piadas) e gozações, como as pessoas gordas, os muito magros, os do interior rural, os sem dentes, os efeminados, os muito estúpidos e quaisquer outros identificados como "desviantes".

Mas se $\mathrm{o}$ ato de mandar bocas é justamente trazer à tona a (homo)sexualidade do outro de maneira pública, com estrilo, denunciando-a, não estaríamos aqui incorrendo em um paradoxo? Eu respondo que não, se considerarmos que além de uma estratégia eficaz de contenção da heteronorma, na medida em que no ato do mandar bocas as fronteiras entre a norma e o desvio são discursivamente reestabelecidas e o desvio é denunciado performativamente, o mandar bocas também é uma estratégia, de acordo com os gays cabo-verdianos, de silenciamento; mas silenciamento dos desejos dos 
acusadores, que almejam com aquela performance masculinista, disfarçar seus próprios desejos em estabelecer relações com parceiros do mesmo sexo (Miguel, 2014).

Se até agora privilegiei os dados da dissertação de Rodrigues acerca do sentido de silenciamento que está contido na categoria "hipocrisia" entre os homossexuais de Cabo Verde, faço-o porque esta autora apresenta bons dados a esse respeito e sua análise merecia uma reflexão e contraposição crítica. Mas mesmo no Mindelo, a não confrontação e o silenciamento são tão fortes que podem ser verificados em meu próprio diário de campo. Reproduzo dois trechos, a respeito do jovem Leandro e da traveste Sandrinho, da Ilha de São Vicente, entre muitos outros possíveis:

\footnotetext{
Leandro falou sobre como ele enxergava o que ele chamou de "comunismo moderno" em Cabo Verde. Não entendi direito o porquê da expressão, mas ele dizia sobre o processo de vivência da homossexualidade no que parecia o sistema "don't ask don't tell" (não pergunte, não diga), apesar de não fazer referência aos EUA ou usar esta expressão inglesa. (Diário de Campo, p.199)

E aí quando você está a fim? Você leva na sua casa? Você pode levar na sua casa?

Sim. Já teve alguns que eu já levei pra casa. Mas é meio arriscado (risos).

Por que? Sua avó e seu primo não sabem?

Sabem, sabem. Minha família inteira sabe. Porque minha opção sexual é um... Um homossexual.

Mas eles não gostam então?

Não... Gostar, gostar, no fundo, não gostam, agem normal.

Mas tem problema de levar os caras em casa ou você que não gosta de levar?

Eu não gosto de levar. Mas se levar é como amigo, nada como um parceiro.

(Entrevista Sandrinho. Mindelo, o9/10/2013)
}

O silenciamento, contudo, não é algo exclusivo da sociedade crioula de Cabo Verde. Como nas sociedades mediterrâneas e sulamericanas, onde o conceito de honra é fundamental e a masculinidade é uma performance pública rigorosamente vigiada, parece que também na sociedade cabo-verdiana "todo hecho, nada dito" (tudo feito, nada dito) (Murray, 1996:246), ou pelo menos feito sem "estrilo" (escândalo), para usarmos uma categoria do próprio crioulo cabo-verdiano.

\section{“Contradição"}

Contudo, subamos ao Barlavento, região norte do arquipélago, pois será na Ilha de São Vicente que se apresentará mais claramente o segundo aspecto central do que chamo de "Sistema Hipocrisia": aqui, à diferença do significado captado por Rodrigues na capital Praia, a categoria "hipocrisia” irá nomear e acusar uma suposta contradição entre valores heteronormativos e práticas homoeróticas. Mais precisamente, a suposta contradição estaria no uso de uma linguagem heteronormativa para as experiências homoeróticas.

Uma formulação local para a diferença das experiências em relação à homossexualidade, ou em outros termos, para os diferentes modelos (homo)sexuais, é fornecida por uma professora universitária na Praia:

Ela comparou os gays de Praia e do Mindelo. Segundo ela, enquanto os de Praia seriam mais discretos, os gays do Mindelo seriam mais "folclóricos". "Muitas pessoas travestidas", disse-me. Contou-me que tem colegas homens e mulheres gays, mas que não se expõem. Enquanto no Mindelo seria diferente. (Diário de campo, p.22) 
Assim, não se trata obviamente de uma dicotomia "folclórico/contido" ou "moderno/tradicional" ou "menos avançado/mais avançado" entre as ilhas de Santiago e de São Vicente, como querem muitos dos cabo-verdianos interessados nesta temática, mas de formas distintas e complexas sobre como uma sociedade vai lidar com determinado fenômeno humano inevitável, como o são as experiências homoeróticas. A diferença dos modelos encontrados em Praia e no Mindelo, são respectivamente, muito próximos dos modelos teorizados por Fry (1982). Contudo, ressalto que, reproduzindo as relações de gênero mais amplas do país, o "modelo hierárquico" parece ter uma hegemonia neste, enquanto o "modelo simétrico", somente aos poucos, começa a ganhar terreno em ambas as ilhas.

\begin{abstract}
Chegamos à conclusão de que talvez deveríamos focar na questão que Didi já havia me indicado em conversa no facebook: a de que os "homossexuais não se relacionam com homossexuais". Elzo e Didi disseram que quando dois "homossexuais" se relacionam são categorizados como "lésbicas". Pela lógica sexista binária, que me explicaram, de que ser homossexual aqui é ser efeminado, que é igual a ser mulher. Dois homossexuais que se relacionam, são duas mulheres que relacionam. E a isso dão o nome de "Lesbianismo". (Diário de Campo, p.42)
\end{abstract}

Suspeito que haja outro aspecto pressuposto nesta associação, que não somente a adequação das identidades homossexuais dentro de um sistema de gênero binário, tal qual sugere o modelo hierárquico de Fry (1982). Judith Butler em Bodies That Matter (1993), dá o exemplo de um cartoon, em que a enfermeira/parteira com o bebê recém-nascido no colo, ao invés de exclamar "é menina!", exclama: “é lésbica!”. E a autora afirma:

\footnotetext{
Longe de ser uma piada essencialista, a apropriação queer do performativo imita e denuncia tanto o poder vinculante da lei, que impõe a heterossexualidade, quanto a sua 'expropiabilidade”" (Butler, 1993:232).
}

A associação "homossexualidade masculina" = "mulher" é um artifício adaptativo do modelo hierárquico no Sistema Hipocrisia, que por ter como base uma ideologia sexual binária (macho e fêmea), tenta encaixar a homossexualidade masculina dentro da categoria "mulher", reatualizando a assimetria de gênero. A brincadeira da acusação de lesbiandade pode ser, por outro lado, uma forte evidência do caráter queer dos sampadjudus. Afinal, tal qual a enfermeira, aqueles que enunciam a lesbiandade entre dois homens gays não o fazem pela fidedignidade conceitual ou simbólica, por realmente acreditar que se trata de lesbianismo ou por desconhecer o conceito, mas por uma jocosidade metafórica que denuncia a própria falseabilidade das identidades de gênero neste sistema, sejam os denunciantes sujeitos gays ou não.

Assim, acrescento o relato do ativista LGBT Elzo, em entrevista, para reforçar o argumento:

\footnotetext{
Sim. Por exemplo, eles acham que todo gay é feminino. A maioria trata todos os gays por adjetivo feminino, por "elas" e tananan... E não sei, não vem a gente como homem que gosta de homem. Eles vêem meio "é afeminado, é mulher, né?". É mais essa ideia de que a gente é meio feminino.

Mas entre vocês, vocês também não se tratam às vezes no feminino?

Sim, sim... (risos) A gente se trata muito no feminino, mas isso não sei... (risos). Acho que tanto desse costume deles tratarem a gente no feminino, que a gente acaba se tratando mesmo entre si no feminino. E, mais... Não é. Mais uma... carinhoso, né? mais carinho. Não é no gozo nem porque você ache que a pessoa seja mulher ou esse tipo de coisa. (Entrevista Elzo. Mindelo, 30/o9/2013)
}

Tal associação não é novidade na literatura etnográfica, caso muito semelhante já fora descrito em relação às "bichas" e aos "homens" das classes 
populares de Belém, no Brasil, nos anos 1970 (Fry, 1982). As semelhanças dentro do mundo lusófono já é tema antigo entre pesquisadores, inclusive comparando diretamente Cabo Verde ao Brasil (Romano, 1964), mas o que isso nos importa aqui? Em primeiro lugar, não acreditar ingenuamente que se trata de um sistema absolutamente autóctone e, em segundo lugar, tentar perceber as especificidades encontradas no Mindelo do século XXI.

Desta forma, se os interlocutores gays do Mindelo se chamam frequentemente no feminino e o fazem conscientes de que não se consideram propriamente "mulheres", como esclarece Elzo, um dos líderes do movimento LGBT local, é seguro afirmar que os demais - os não gays12 - têm a plena dimensão de que os gays e as travestes não são "mulheres". Os sujeitos não gays reconhecem uma distinção clara entre sujeitos gays e mulheres. Assim, a brincadeira difusa no Mindelo de classificar dois homens homossexuais que se relacionam entre si enquanto "lésbicas", parece-me evidenciar um reforço do binarismo sexual por um lado e, ao mesmo tempo e paradoxalmente, uma postura queer de alguns sampadjudus, que neste ato de enunciação performativa subvertem e denunciam o próprio sistema binário no qual estão inseridos. Mas precisamos aprofundar ainda mais no que tange à "hipocrisia".

Assim, aproveito para trazer algumas referências captadas no Mindelo em relação a esta categoria. Ela aparece diversas vezes na entrevista da traveste Suzete, presidente da associação gay local. Na primeira delas, ela se refere ao episódio histórico do movimento LGBT local, em que diversos homossexuais saíram pela primeira vez travestidos pelas ruas do Mindelo em plena luz do dia na década de 1990, como estratégia de aniquilamento da "hipocrisia”, já então diagnosticada:

Eu faço parte dos pioneiros gays cabo-verdianos. Os que deram, os que disseram "basta a hipocrisia", "basta a discriminação".

(Entrevista Suzete. Mindelo, 29/10/2013)

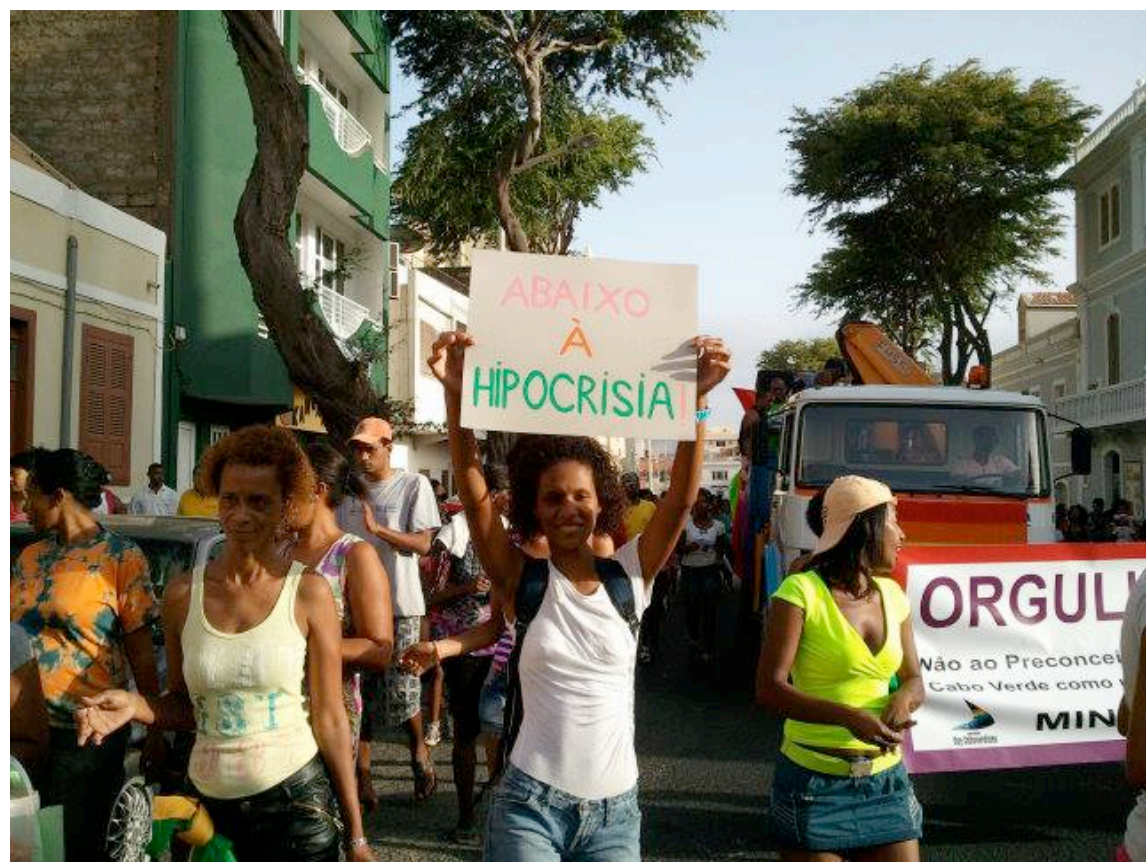

12 Por sugestão vocabular da traveste Suzete, chamarei de sujeitos "não gays" todos aqueles homens que não se reconhecem enquanto portadores de uma identidade "gay", ainda que tenham experiências homoeróticas frequentes. 
Fig.1 - Manifestante carregada um cartaz contra a "hipocrisia" no primeiro Mindelo Pride, em 2013. FONTE: Divulgação/Página do Facebook da Associação Gay Caboverdiana

A "hipocrisia" também aparece na entrevista de Suzete para descrever que a homossexualidade deve ser exercida discretamente, evidenciando o sentido de silenciamento e ressignificando a crítica entre os "homoafectivos" de Praia, conforme nos apresentou Rodrigues.

\begin{abstract}
E... Como é que a relação dos parceiros do mesmo sexo aqui no Mindelo? Como é que... Como é que se conhecem pessoas do mesmo sexo? Como é que se dão as relações?

As relações são bem... Bem bonitas. Mas como disse, a nossa sociedade ainda é um bocadinho hipócrita. Então é uma relação bem... toda aí atrás do muro, "ah, não pode saber", "ah minha família não pode saber" ou "não venha me visitar", "mas discreto", "não venha...". É tudo uma base de hipocrisia, mas na cama, é um "ó". Na cama, bofe é escândalo. (risos)

(Entrevista Suzete. Mindelo, 29/10/2013)
\end{abstract}

A mesma categoria aparece na entrevista de Suzete, dessa vez, para descrever a suposta contradição (e decepção, diga-se de passagem) entre uma performance discursiva de gênero tradicionalmente masculinista e uma perfomance sexual passiva, esta atribuída quase sempre ao feminino em Cabo Verde, seja à mulher seja ao sujeito gay:

\begin{abstract}
Mas eles [os rapazes não gays] são sempre ativos?
Ah, olha, em toda a parte do mundo seria bem hipócrita... E não... Não serei coerente se não responder perante a nossa sociedade. A nossa sociedade é hipócrita. Não, é muita mentira... [...] Não, muita mentira. Porque já tive homens na cama, "Ah, eu sou homem assim". De dia ou na noite, latejando. Mas na cama, tive várias presas, que fiquei com a cara: "oh, eu que tenho que fazer o ativo? E você é o machão?". Eu fazer "uhum". Mas fazer o que? Com toda aquela carne, que desperdício, né?

(Entrevista Suzete. Mindelo, 29/10/2013)
\end{abstract}

Percebe-se nas palavras e no tom, que há algo de acusatório na suposta contradição. Se por um lado a sociedade projeta nos homens homossexuais as expectativas de feminilidade e de passividade sexual, entre outros atributos, os próprios homossexuais esperam encontrar nos rapazes não gays, a masculinidade, a virilidade, o falo rígido e grande e a performance de ativos sexuais, aproximando-se dos pressupostos do "modelo hierárquico" de Fry (1982). Essa expectativa acaba por reproduzir uma jocosidade depreciativa do feminino, como "presa", que acaba por reproduzir o próprio sistema machista cabo-verdiano. Isto fica muito claro na fala de Tita, uma traveste mindelense que conheci na Praia, publicada por um jornal local: "Gosto de homens românticos, quando estou cansada, de ressaca, mas quanto ao resto gosto de homens muitíssimo cavalo, com $\mathrm{H}$ maiúsculo, detesto homem boneca" (A Nação Online, 19/07/2012)13.

Para a maioria dos gays e das travestes no Mindelo, não é um problema que um homem goste de ser passivo sexual. O problema para eles e elas é

13 De certa forma, esta fala de Tita aponta para uma maior cautela na leitura performativa do gênero, típica da teoria queer butleriana. Contestando o caráter performativo das experiências transexuais, Prosser afirma: "há trajetórias 'transgenerificadas' e, em particular, trajetórias transexuais, que almejam aquilo que esse esquema (ou seja, a performatividade) desvaloriza. Em outras palavras, há transexuais que buscam, em vez disso, ser constativos, que simplesmente buscam ser (Prosser, 1998:32). Assim, Tita - e outras diversas travestes com quem convivi - se estão em seus corpos bricolando uma nova possibilidade de gênero, em seus discursos, porém, há um ideal de gênero tradicional a ser alcançado, ser mulher, substanciada e ontológica, em conformidade com o binarismo do próprio Sistema Hipocrisia. Por outro lado, sua postura em não conceder ao Estado o poder de reconhecimento de suas afetividades e corpos parecem de alguma forma realizar o projeto político defendido por Butler: "Ser legitimado pelo Estado é aceitar os termos de legitimação oferecidos e descobrir que o senso público e reconhecível da pessoalidade é fundamentalmente dependente do léxico dessa legitimação" (Butler, 2003:226). 
quando se espera que alguém que se diga "macho" frustre, por hipocrisia, as expectativas dos gays. Afinal de contas, trazer as marcas da "homossexualidade" (ou do "feminino") no corpo, como fazem os gays e as travestes, tem alguns ônus para os próprios14. Entre os ônus, o estigma, pois lá como cá, impera o estigma do passivo sexual (Misse, 2007). Estigma que os sujeitos que tem uma postura de passividade no sexo, mas que não se identificam como "homossexuais" ou que "não se assumem" publicamente enquanto tais "se livram". Isso gera certo desprezo para com esses sujeitos "héteros com aspas". Mas por que esses homens "não se assumem"? Suzete sugere uma explicação:

E eles não se consideram gays?

Ah, não é que se consideram, é hipocrisia. Eles, sabe? Eles têm medo da, da reação da sociedade. Então se oprimem ou se auto-discriminam, não sei.

(Entrevista Suzete. Mindelo, 29/10/2013)

Em Cabo Verde, alguns homens, por razões diversas, não incorporam a identidade homossexual, ainda que habitem o universo do homoerotismo, sendo alguns deles, inclusive, "passivos" no ato sexual. Eles exercem frequentemente sua sexualidade com os homossexuais e esta identidade "não gay" é uma possibilidade disposta na cultura cabo-verdiana. Uma das razões da não incorporação identitária se explica pelo papel sexual que desempenham majoritariamente dentro do modelo hierárquico: são ativos no coito (penetram) e este signo não está associado ao feminino e, por extensão, à "homossexualidade" em Cabo Verde. Mas a "passividade" não é o único signo do universo semântico da "homossexualidade" no modelo hierárquico, existe um universo de vocábulos, expressões corporais, gostos e atitudes que pressupõem a feminilidade, a "homossexualidade" ou o "sujeito homossexual". Além disso, levando a sério os nativos, é possível também que alguns homens não "assumam" uma identidade gay, pelo simples receio de serem discriminados, ainda que nenhum desses rapazes não gays tenha me explicado sua identidade por essa via.

Como tratei em outro lugar (Miguel, 2014), o mandar boca não será sempre ou por todos entendido como "homofobia", no sentido de um discurso de ódio contra homossexuais. Da perspectiva dos sujeitos gays nativos, a atitude dos rapazes não gays não é necessariamente "homofóbica", mas hipócrita, porque tem por intuito final quase sempre obter uma relação sexual com eles, revelando mais um aspecto da sexualidade masculina em Cabo Verde.

\section{Considerações finais}

Espero que tenha ficado claro para o leitor que a categoria de acusação "hipocrisia", mencionada tanto na cidade da Praia quanto na cidade do Mindelo, possui dois significados distintos, mas frequentemente acionados pelos sujeitos homossexuais de Cabo Verde: ela serve tanto para acusar o silenciamento social diante da evidência empírica da homossexualidade, como também serve para acusar a convivência e propagação da heteronorma principalmente por aqueles homens que habitam o universo homoerótico, o que se configuraria, segundo os sujeitos gays, como uma contradição.

14 Vale lembrar que também os "homossexuais" ou "homoafectivos" masculinos no modelo simétrico de Fry tendem igualmente a performar um gênero que escape desses ônus, como fica claro nos exemplos retirados da etnografia de Carmen Dora Guimarães (2004). 
Por último, as dinâmicas do sistema de gênero em Cabo Verde têm como ideal preservar ao máximo a heteronorma, ainda que a homossexualidade seja algo culturalmente possível. Assim, a performatividade dos rapazes não gays em suas abordagens sexuais aos gays é perpassada por signos de masculinidade até que o ato homossexual consumado estrangule a possibilidade de coerência (para os sujeitos gays) entre a heteronorma e a prática homossexual. Mas os sujeitos gays não estão imunes às tradições e mantém, muitas vezes, o jogo sexista que pressupõe papeis muito definidos de cada um dos gêneros, entre eles, uma hipermasculinidade dos rapazes. Para silêncios e supostas contradições, os gays em Cabo Verde têm preterido a acusação de "hipocrisia". E talvez estejam também falando de si mesmos.

\section{Referências bibliográficas}

AMPOFO, A. A.; BOATENG, J. Multiple meanings of manhood among boys in Ghana. In: TAMALE, S. (Ed.). African Sexualities: a reader. Dakar: Pambazuka Press, 2011. p. 420-436.

A NAÇÃO ONLINE. (19 de Julho de 2012). Tita: "Gosto de 'homem cavalo' com $\mathrm{H}$ maiúscula". Disponível em: http://www.alfa.cv/anacao_online/sociedadeconteudo/2913-tita-qgosto-de-homem-cavalo-com-hmaiusculaq?tmpl=component\&print=1\&layout=default\%E2\%80\%A61/2Criado em12-07-19Tita

BORDONARO, L. Masculinidade, violência e espaço público: notas etnográficas sobre o Bairro Brasil da Praia (Cabo Verde). Tomo. Revista de Pós-graduação e Pesquisa em Sociologia, 21: 101-136, 2012.

BUTLER, J. Bodies That Matter: On the Discursive Limits of Sex. New York: Routledge, 1993.

BUTLER, J. ([2002] 2003). O parentesco é sempre tido como heterossexual? Cadernos Pagu (21) , pp. 219-260.

DIAS, J. (2000). Entre Partidas e Regressos: tecendo relações familiares em Cabo Verde. Dissertação de Mestrado. Departamento de Antropologia Social. Universidade de Brasília.

DUMONT, Louis. Homo Hierarchicus: o sistema das castas e suas implicações. 2. ed. São Paulo: EDUSP, 1997.

FRY, P. Da Hierarquia à Igualdade: A Construção Histórica da Homossexualidade no Brasil. In: P. FRY, Para Inglês Ver: Identidade e Política na Cultura Brasileira (pp. 87-115). Rio de Janeiro: Zahar Editores, 1982.

GUIMARÃES, C. D. O Homossexual visto por Entendidos. Rio de Janeiro: Garamond, 2004. 
LOBO, A. Tão longe e tão perto. Emigração feminina e organização familiar: Boa Vista - Cabo Verde. In: M. I. GRASSI, Género e Migrações Cabo-Verdianas. Lisboa: Imprensa de Ciências Sociais, 2007.

LOBO, A. Tão Longe Tão Perto - Famílias e "Movimentos" na Ilha de Boa Vista de Cabo Verde. Praia: Edições Uni-CV, 2012.

LOBO, A.; MIGUEL, F. "I want to marry in Cabo Verde": Reflections on homosexual conjugality in contexts. Vibrant: Virtual Brazilian Anthropology, v. 12, n. 1, p. 37-66, jun. 2015.

MASSART, G.. Masculinités pour tous? Genre, pouvoir et governementalité au Cap-Vert. Lusotopie, 1(2) , pp. 245-262, 2005.

MASSART, G. The aspirations and constraints of masculinity in the family trajectories of Capean Verdean men from Praia (1989-2009). Etnográfica, v. 17, n. 2, p. 293-316, 2013.

MIGUEL, F. "Levam má bô":(homo)sexualidades entre os sampadjudus da Ilha de São Vicente de Cabo Verde. Dissertalção de Mestrado em Antropologia Social. Universidade de Brasilia, 2014.

MIRANDA, J. M. Constituição de Masculinidades num Contexto de Crise do Pescado: uma abordagem em Rincão, Santiago, Cabo Verde. Dissertação de Mestrado. Praia: UniCV, 2013.

MISSE, M. O estigma do passivo sexual: um símbolo de estigma no discurso cotidiano. Rio de Janeiro: Booklink, 2007.

MURRAY, S. O. Male Homosexuality in Guatemala: Possible Insights and Certain Confusions from Sleeping with the Natives. In: E. LEWIN, \& W. L. LEAP, Out in the Field (pp. 236-260). Chicago: University of Illinois Press, 1996.

PROSSER, J. Second Skins: The Body Narratives of Transsexuality. New York: Columbia University Press, 1998.

RODRIGUES, C. A Homoafectividade e as relações de género na Cidade da Praia. Dissertação de Mestrado . Praia, Cabo Verde: UniCV, 2010.

RODRIGUES, I. P. As mães e os seus filhos dentro da plasticidade parental: reconsiderando o patriarcado na teoria e na prática. In: M. GRASSI, \& I. ÉVORA, Género e Migrações Cabo-Verdianas. 2007.

ROMANO, L. Cabo Verde - o elo antropológico entre África e o Brasil? Ocidente. Vol. 66 n. 312 p.177-189, 1964.

VASCONCELOS, J. "Manera, ess Muv?": mobilidade como valor em São Vicente de Cabo de Verde. In: J. B. DIAS, \& A. d. LOBO, África em Movimento (pp. 4962). Brasília: ABA Publicações, 2012. 